\title{
Realidade Aumentada - Estudo de caso de utilização em contextos históricos
}

\section{Realidad Aumentada - Estudio de caso de utilización en contextos históricos}

\author{
Augmented reality - Case study use in historical contexts
}

\author{
José Maia \\ Instituto Politécnico de Portalegre, Portugal \\ jmaia@ipportalegre.pt
}

\section{RESUMO}

O presente artigo relata o processo da criação de conteúdos de Realidade Aumentada em contextos educativos, utilizando como estudo de caso um espaço museológico da época romana. Centra-se essencialmente na descrição do processo pedagógico e metodológico utilizado no quadro das aulas de Produção Multimédia, e visando a motivação dos alunos e a melhoria dos resultados finais refernetes aos projectos desenvolvidos pelos mesmos.

Palavras chave: Realidade Aumentada, Ilustração, Animação, Metodologia de Ensino

\section{RESUMEN}

Este artículo informa sobre el proceso de creación de contenido de Realidad Aumentada en contextos educativos, utilizando como estudio de caso un espacio de museo de la época romana. Se centra principalmente en la descripción del proceso pedagógico y metodológico utilizado en el marco de las clases de Producción Multimedia, y apunta a la motivación de los estudiantes y la mejora de los resultados finales referidos a los proyectos desarrollados por ellos.

Palabras clave: Realidad Aumentada, Ilustración, Animación, Metodología de Enseñanza

\section{ABSTRACT}

This article reports the process of creating Augmented Reality content in educational contexts, using as a case study a museum space from Roman times. It focuses mainly on the description of the pedagogical and methodological process used in the framework of the Multimedia Production classes, and aiming at the motivation of the students and the improvement of the final results referring to the projects developed by them.

Keywords: Augmented Reality, Illustration, Animation, Teaching Methodology 


\section{Introdução}

A Realidade Aumentada (AR) assume-se como uma das mais relevantes tecnologias no contexto actual, a utilização de gráficos gerados tecnologicamente por via digital é potenciadora de um inegável impacto visual . Enquanto tecnologia , a AR potencia assim a adição de elementos virtuais gerados digitalmente ao mundo real de forma síncrona. A fim de potenciar que isto possa ocorrer, torna-se necessário o registro de objetos virtuais com um rastreamento preciso ou uma estimativa de pose da câmara, mas o rastreamento é um dos principais desafios técnicos do sistema AR (Comport, Marchand, Pressigout, \& F. , 2006).

As possibilidades são assim, ilimitadas para esta tecnologia, assim como a transversalidade da mesma no quadro de diversos contextos de utilização desde a Saúde, à Educação, à Engenharia e praticamente todas as áreas podem beneficiar desta tecnologia . No caso concreto deste projeto a mesma foi utilizada a fim de conferir mais valias a um local histórico, valorizando o património encontrado no local e ampliá-lo por via da realidade Aumentada, a génese deste projeto emergiu em contexto de Educação, no quadro das aulas de Produção Multimédia de um curso ministrado por um Politécnico Português nas áreas do Design, da Animação e Multimédia. O projeto em questão tinha objectivos iniciais bem definidos, nomeadamente:

1- Interessar os alunos pela temática, através de estímulos que efectivamente os guiassem e direcionassem no sentido de querer efectivamente aprender e articular as tecnologias necessárias para desenvolver o projeto. Kester et al (2018) considera que o processo de aprendizagem é por vezes é descrito essencialmente como uma interação entre professor, aluno, assunto e ferramenta. Neste caso concreto a abordagem consistiu em criar uma necessidade de aprendizagem a fim de potenciar a resolução de um problema inerente a uma instituição local através do recurso às capacidades técnicas dos alunos, suscitando-Ihes efectivamente a necessidade de querer explorar de forma mais exaustiva as mesmas.

2- Criar um storytelling baseado em histórias e nomes extraídos de epígrafes gravadas em matérias sólidas do período romano e traduzí-lo para imagens, articulando a a vertente do Design, da ilustração e da Animação digital e combiná-las eficazmente num produto multimédia que efectivamente pudesse ter o potencial de dotar a organização para a qual o mesmo foi desenvolvido de um produto estética e visualmente apelativo que, paralelamente, tivesse potencial de intervir ao nível da construção da sua própria experiência de Marca.

3- Motivar os alunos na relação pedagógica, permitindo-Ihes adquirir e articular conceitos inerentes à temática a trabalhar e adquirir aptidões técnicas e práticas metodológicas inerentes à consecução do projeto.

\section{Estrutura conceptual}

Existem muitas definições e caracterizações de RA e o domínio não está completamente definido, mas a essência da tecnologia de RA é que o mundo físico é expandido com elementos virtuais (De Lange \& Lodewijk, 2017). De uma forma genérica a realidade aumentada consiste na criação de ambientes simbióticos entre real e virtual através da utilização de um dispositivo tecnológico. Neste caso e de uma forma simplista ao vídeo capturado em tempo real são sobrepostos de forma síncrona objetos virtuais, que podem ser outros vídeos ou elementos tridimensionais, provocando assim a imersão do utilizador num misto entre ambiente real e virtual. Pode ser assim abordada cia perspectiva que se trata de uma forma de alterar a realidade, definindo-se assim como a tecnologia que por via do uso de computadores permite melhorar a riqueza do mundo real (Bederson, 1995). É assim uma tecnologia que permite ao utilizador transportar o ambiente virtual para o seu espaço em tempo real, utilizando um dispositivo tecnológico, podendo usar a interface do ambiente real para manusear os objetos reais e virtuais (Silva, 2013).

\section{Metodologia}

Em termos de abordagem à temática a mesma baseouse na metodologia de projeto multimédia enunciada por Ribeiro (2012). Planeamento, nesta fase apresentou-se o tema através do website da entidade, para que os alunos assimilassem uma panorâmica geral do que se tratava, posteriormente particularizou-se através da apresentação de fotografias da sala de Epigrafia do Museu, onde puderam observar fotograficamente cada uma das Aras expostas no Museu.

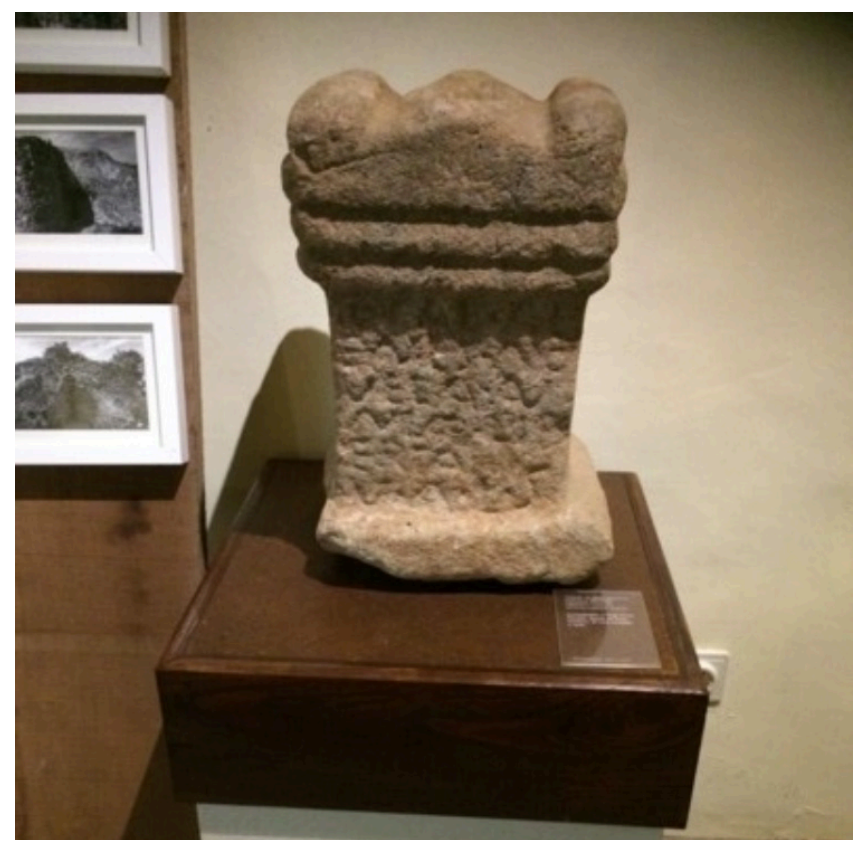

Figura 1- fotografia de ara, elemento exemplificativo do ponto de partida do projeto 
De forma gradual, os alunos começaram a absorver o espirito do projeto e a realizar a sua própria investigação sobre o contexto histórico e social ao qual estes objetos se referiam, posteriormente, detalhou-se os objetos contidos nesta sala através de uma apresentação realizada em contexto de sala de aulas por uma técnica afeta ao Museu, nesta sessão abordou-se cada uma das aras de forma detalhada, incidindo essencialmente nos fragmentos de história que as mesmas perpetuaram no tempo. Por fim realizou-se uma visita ao espaço, com visita guiada, que permitu pela primeira vez que os alunos tivessem contacto com as peças físicas propriamente ditas, podendo assim sentir o que as mesmas lhes transmitiam, antes de as reproduzirem e integrarem nos seus projectos individuais que consistiriam na criação de um livro ilustrado com páginas que despoletariam realidade aumentada por via de um aplicativo móvel. Durante esta etapa pretendeu-se essencialmente construir todo um corpus ao projeto que posteriormente se materializasse num produto multimédia. Depois de aquisição de todos os insights que permitissem sentir o projeto procedendo-se à criação de um storytelling associado ao mesmo, neste caso concreto tendo como ponto de partida os registos epigráficos enunciados nas aras, extraindo destes fragmentos de história, personagens e eventos que permitissem completar essas histórias criando um storytelling coerente e apelativo. De seguida procedeuse à fase de Design, nesta fase procedeu-se à construção de todas as ilustrações, animações e elementos visuais a incluir no aplicativo.

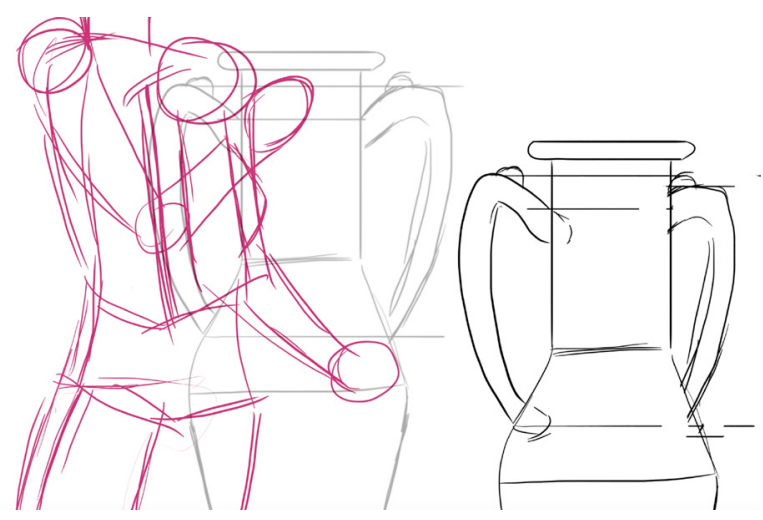

Figura 2- Exemplo de ilustração

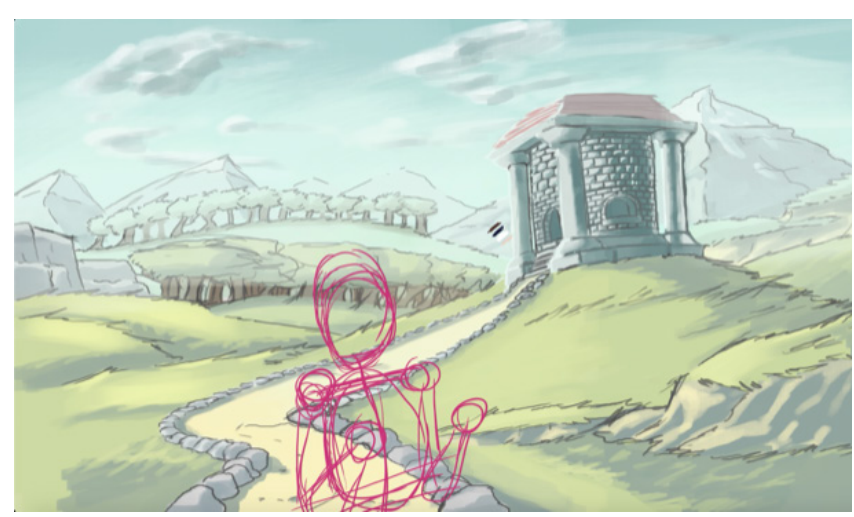

Figura 3- Exemplo de cenário com base de animação
De seguida a fase de Autoria Multimédia, onde efectivamente se procedeu ao mapeamento de um mínimo de três ilustrações por cada um dos livros desenvolvidos e de seguida à autoria multimédia em software Unity 3D, onde se ajustaram posicionamentos, trackings e sons dos diversos aplicativos. Durante a fase de testes, procedeuse à realização de diversos testes a fim de conferir a funcionalidade das apps quando confrontadas com os marcadores definidos nos livros físicos desenvolvidos, assim como a uma análise confirmaria que todos os ícones e exigências das plataformas estavam efectivamente cumpridos.

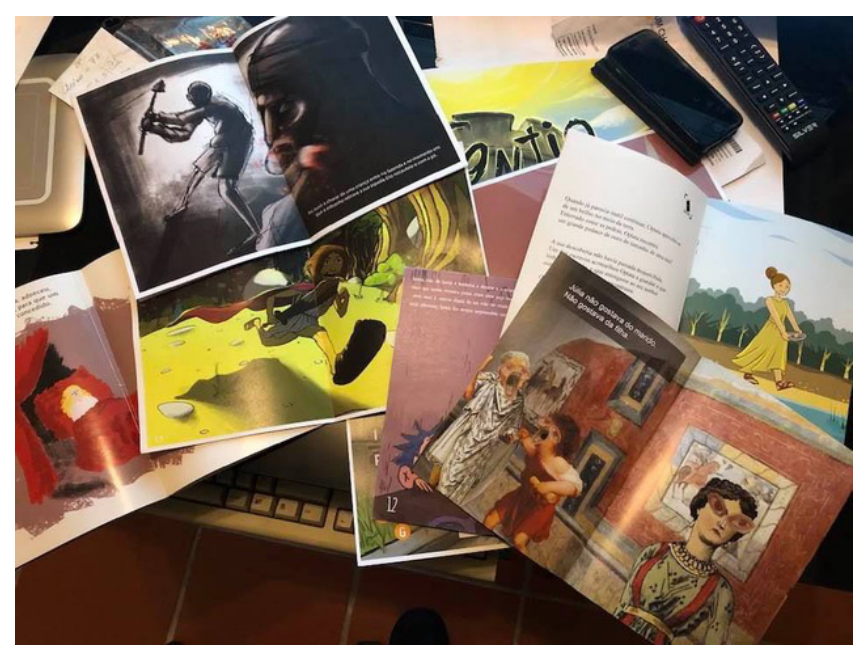

Figura 4- Teste da realidade aumentada nos diversos livros desenvolvidos

Por fim a Conclusão onde se procedeu à compilação de todas as apps para dispositivos móveis Android, aguardando-se neste preciso momento oportunidade para apresentar e distribuir os projetos.

\section{Conclusões}

De uma forma geral considera-se que a forma de abordar o projeto efectivamente foi compensadora, uma vez que permitiu aos alunos ter a noção como se aborda um projeto multimédia em contexto real de trabalho. Os métodos de ensino/ aprendizagem também beneficiam claramente do entusiasmo que esta tipologia gera nos alunos, pois o facto de sentirem a existência de uma extrapolação de um contexto meramente académico assume-se como um inegável fator motivacional. Do lado de quem ensina, efectivamente também aqui há um desafio inerente, o de alunos motivados que querem aprender a fazer, uma vez que sentem uma necessidade disto, neste sentido, o workflow do projeto torna-se fluido e menos penoso, reduzindose assim a curva de aprendizagem inerente a softwares e tecnologias de grande exigência como é o caso do Unity e da própria Realidade Aumentada. De destacar que num total de 32 alunos que constituíam a turma foram entregues 27 projectos completos. O impacto visual e as mais valias inerentes para a instituição para a qual foi desenvolvido o projeto também são um fator a destacar, uma vez que ficam 
dotadas de um produto de grande impacto visual, inovador e que Ihes confere claramente mais valias em termos da criação de uma experiência de marca, questão que também atua de forma transversal para a própria escola, como para os próprios alunos como futuros profissionais, que se vêm assim dotados de um projeto em portfólio que os dignifica a este nível.

\section{Bibliografia}

Bederson, B. (1995). Audio Augmented Reality: A Prototype Automated Tour Guide. In Conference Companion on Human Factors in Computing Systems. New York.

Comport, A., Marchand, E., Pressigout, M., \& F. , C. (4 de 2006). Real-time markerless tracking for augmented reality: The virtual visual servoing framework. . IEEE Transactions on Visualization and Computer Graphics., 12, pp. 615-628.

De Lange, R., \& Lodewijk, M. (2017). Virtual Reality \& Augmented Reality in het primair onderwijs -- een literatuurstudie en verkennend onderzoek. Obtido de https://www.nro.nl/wp-content/uploads/2017/02/067Antwoord-Virtual-Reality-en-Augmented-Reality-in-hetprimair-onderwijs-2019.pdf

Kester, L. e. (2018). Docent en leerling aan het stuur. Onderzoek naar leren op maat met ict. Obtido de nro. nl: https://www.nro.nl/wp-content/uploads/2018/02/ Doorbraakproject-Onderwijs-ICT_Eindrapport.pdf

Ribeiro, N. M. (2012). Multimédia e Tecnologias interactivas (5 ed.). Lisboa: FCA.

Silva, A. S. (2013). Uso de Recurso Educacional com Mídias Interativas e Integradas On-Line em Ensino e Aprendizagem. UNIVERSIDADE FEDERAL DE ITAJUBÁ. 